\title{
The characteristics of breast cancer patients with metachronous primary malignancies
}

\author{
Beata Sas-Korczyńska ${ }^{1}$, Wojciech Kamzol ${ }^{1}$, Marta Kołodziej-Rzepa ${ }^{2}$, Wojciech M. Wysocki ${ }^{2}$
}

Introduction. The risk of developing subsequent primary cancers varies from $1 \%$ to $18 \%$ and it depends on the type of first cancer and treatment methods applied. Considering the time of occurrence, multiple primary cancers generally fall into two categories: synchronous and metachronous. In breast cancer patients, $10.5 \%$ developed multiple primary cancers, from which $23.8 \%$ had synchronous, $79 \%$ had metachronous and the remaining $2.8 \%$ had both synchronous and metachronous malignancies. In patients with breast cancer, elevated risk is observed especially in the development of contralateral breast cancer, endometrial cancer, esophageal cancer, ovarian cancer and thyroid cancer.

Aim. This paper presented the characteristics of breast cancer patients with metachronous primary malignancies in relation to the type of metachronous primaries (breast versus non-breast) and to analyse the impact of the type of metachronous cancers on survival rate.

Material and methods. Among patients treated for breast cancer between 1963 and 2010, 354 patients (2.1\%) developed metachronous primary malignancies and these made up $13.8 \%$ of all patients with multiple primary cancers. The mean age at diagnosis of the first breast cancer was $53 \pm 11.5$ years; positive family cancer history was noted in 127 patients (35.9\%). Metachronous malignancies are defined as primaries following the diagnosis of breast cancer in a time interval greater than or equal to than 6 months. In our group, the mean time interval between the diagnosis of breast cancer and the appearance of metachronous malignancies was 100.9 \pm 74.9 months (range: 6-543 months, median: 83 months). For comparison of the two groups (patients with second breast vs non-breast cancer) we used the Pearson's Chi-square test for independence (for categorized variables) and variance analysis with Student's t-test (for continuous variables). The survival rate was evaluated with the Kaplan-Meier method, and the log rank test was applied to assess the influence of some factors on the evaluated results. The significance level at $\alpha=0.05$ was adopted for all statistical analyses. Results. The probability of occurrence of new cancer averaged from $38.1 \%$ to $67.8 \%$ for 5 and 10 years after diagnosis of first breast cancer, respectively. In our group, 380 cases of metachronous carcinomas were noted in 354 analysed patients. The most frequent metachronous malignancy was breast cancer (194 cases — 54.8\%), which occurred as second (192 cases) or third (2 cases) cancer. Patients with contralateral breast cancer in comparison to other types of metachronous malignancies were significantly ( $p<0.05$ ): younger (under 50 years: $56.2 \%$ vs $34.4 \%$ ), premenopausal $(69.6 \%$ vs $48.8 \%$ ), had a lobular type of first breast cancer (6.7\% vs $1.3 \%)$, and rarely received tamoxifen ( $25.3 \%$ vs $48.2 \%)$. The type of metachronous cancers significantly influenced survival rate: 10 -year overall survival rates were $80.1 \%$ vs $67.8 \%,(p=0.0271)$. Conclusions. The risk of occurrence of second malignancies in breast cancer survivors makes early detection of metachronous malignancies obligatory because it is an important factor which influences the quality of life in breast cancer survivors.

NOWOTWORY J Oncol 2017; 67, 1: 14-23

Key words: breast cancer, metachronous malignancies, contralateral breast cancer

${ }^{1}$ Clinic of Oncology, Maria Skłodowska-Curie, Memorial Cancer Centre and Institute of Oncology, Kraków Branch, Poland ${ }^{2}$ Department of Surgical Oncology, Maria Skłodowska-Curie, Memorial Cancer Centre and Institute of Oncology, Kraków Branch, Poland 


\section{Introduction}

The advances in cancer therapy, early detection and supportive care have contributed to the improvement of survival rates. About $70 \%$ of all cancer patients survive at least five years after diagnosis. The number of cancer survivors is growing rapidly, by about $2 \%$ each year. Therefore, the identification of the subsequent effects of cancer and its treatment has become a critical problem due to their long-term clinical and physiological importance. One of these late events is the diagnosis of a new cancer in cancer survivors - a second, third or higher-order primary in some cases [1-6].

Published data indicate that the risk of developing subsequent primary cancers varies from $1 \%$ to $18 \%$, and this depends on the type of first cancer and used treatment methods [3, 6-11].

Causal mechanisms of multiple primary cancer development include genetic predispositions, environmental exposures, lifestyle factors as well as late sequelae of cancer treatment (cytotoxic, radiation or hormonal therapies), its results and a combination of these mechanisms $[1,3,4,5$, $8,9,12,13]$. The risk of second primaries also depends on patient age and the amount of time elapsed since anticancer therapy [3, 4, 14-16]. According to data published by Lee et al., the 30-year overall cumulative incidence of second malignancies amounts to $5.2 \%$ for children (aged $\leq 14$ years), $13.9 \%$ for adolescents and young adults (aged 15-39 years) and $16.8 \%$ for adults (aged $\geq 40$ years) [4].

The definition of multiple primary cancers is based on the classic criteria of Warren and Gates which include 1) the site of origin - tumours arise in different organs than independent primaries, 2) morphology and histology of tumours - each tumour has to be histologically distinctive and the possibility of metastasis or recurrence must be excluded, and 3) the amount of time elapsed since the initial diagnosis $[7,9,10]$. Considering the time of occurrence, multiple primary cancers generally fall into two categories: 1) synchronous, if the cancers occur at the same time or within 2-6 months, and 2) metachronous, if the primaries follow in sequence in a interval time interval of more than 2-6 months [1, 5, 9, 10]. It should be noted that the time interval distinguishing synchronous and metachronous malignancies has not been precisely defined in literature. However, a time interval of 6 months between the occurrence of two primaries has been accepted by some authors [1,9]. Breast cancer is the most common cancer in women; in 2012 it was diagnosed in 1.7 million women in the world, and in 17 thousand women in Poland $[17,18]$. In these patients, continuously improving survival rates have been observed and, therefore, after effective therapy, the majority of them become longterm survivors with elevated risk of occurrence of second malignancies [16, 19, 20-22].
The risk of developing multiple primary malignancies in breast cancer survivors is increased in the case of positive family history, the presence of a mutation in tumour suppressor genes (BRCA1, BRCA2, PTEN, TP53) as well as in survivors with negative family history. Other factors which potentially can influence the risk of second malignancy include age, body weight, alcohol intake, hormonal replacement therapy and breast cancer therapy [15, 20, 22-24].

According to Lee et al., $10.5 \%$ of breast cancer patients had multiple primary cancers, of which $23.8 \%$ had synchronous, $79 \%$ had metachronous and the remaining $2.8 \%$ had both synchronous and metachronous malignancies [9]. In patients with an initial diagnosis of breast cancer, elevated risk is observed especially in the development of contralateral breast cancer, endometrial cancer, esophageal cancer, ovarian cancer and thyroid cancer [7].

The purpose of this study was 1) to present the characteristics of breast cancer patients with metachronous primary malignancies, 2) to compare the characteristics in relation to the type of metachronous primaries (breast versus non-breast) and 3 ) to analyse the impact of the type of metachronous cancers on survival rate.

\section{Material and methods Patients}

Between 1963 and 2010, 17,066 patients with breast cancer were treated at Maria Skłodowska-Curie Memorial Cancer Centre and Institute of Oncology in Krakow. Of these, 354 patients (2.1\%) developed metachronous primary malignancies and they made up $13.8 \%$ of all patients with multiple primary cancers. The mean age at diagnosis of the first breast cancer was $53 \pm 11.5$ years (range: 26-83, median: 51 years). Positive caner family history was noted in 127 patients (35.9\%). Metachronous contralateral breast cancer appeared in 50 patients with breast cancer positive family history, comprising $14.1 \%$ of all patients and $39.4 \%$ of patients with positive family history. Benign breast diseases and/or hormonal disturbances were found in 33 individuals (9.3\%).

The clinicopathological characteristics of 354 patients with first breast cancer and metachronous primary malignancies are presented in Table I.

The majority of these patients (75.2\%) had an early stage (pT1-2) of the disease at the time of diagnosis of first breast cancer; however, in $52.5 \%$ of patients the axillary lymph node metastases were confirmed in pathological examination.

Because patients with first breast cancer and metachronous cancers were managed over a period of 47 years, the diagnostic methods and the spectra of treatment changed along with the indications. Nevertheless, surgery was the primary treatment modality in all presented patients; radical mastectomy was performed in 337 cases $(95.2 \%)$, whereas 17 patients (4.8\%) underwent 
Table I. Characteristics of 354 patients with breast cancer who developed metachronous primary cancers

\begin{tabular}{|c|c|c|}
\hline Parameters (at diagnosis of first breast cancer) & No. of patients & $\%$ \\
\hline Age (years) & 164 & 46.3 \\
\hline$\leq 50$ & 190 & 53.7 \\
\hline \multicolumn{3}{|l|}{$>50$} \\
\hline \multicolumn{3}{|l|}{ Menopausal status } \\
\hline Premenopausal & 213 & 60.2 \\
\hline Postmenopausal & 141 & 39.8 \\
\hline Family history (positive) & 127 & 35.9 \\
\hline Breast cancer & 38 & 10.7 \\
\hline Breast cancer and other cancers & 12 & 3.4 \\
\hline Other cancers & 77 & 21.8 \\
\hline Breast disease and other symptoms & 33 & 9.3 \\
\hline Benign breast diseases (fibrocystic changes, hyperplasia) & 14 & 4.0 \\
\hline Hormonal disturbances (hormone replacement therapy, pregnancy-related breast cancer, adnexitis) & 17 & 4.8 \\
\hline$B R C A 1$ or $B R C A 2$ mutation & 2 & 0.6 \\
\hline \multicolumn{3}{|l|}{ Histological type } \\
\hline Ductal & 298 & 84.1 \\
\hline Lobular & 15 & 4.2 \\
\hline Other ${ }^{\mathrm{a}}$ & 41 & 11.6 \\
\hline \multicolumn{3}{|l|}{ Stage of breast cancer } \\
\hline pT 1 & 77 & 21.8 \\
\hline рт 2 & 189 & 53.4 \\
\hline рт 3 & 43 & 12.1 \\
\hline p 4 & 35 & 10.0 \\
\hline pT $x^{b}$ & 10 & 2.8 \\
\hline $\mathrm{pN} 0$ & 167 & 47.2 \\
\hline $\mathrm{pN}+$ & 186 & 52.5 \\
\hline $\mathrm{pN} \mathrm{x}^{\mathrm{b}}$ & 1 & 0.3 \\
\hline
\end{tabular}

aOther types of first breast cancer: medullary (12 pts.), mucinous (9 pts.), metaplastic (9 pts.), apocrine (3 pts.), tubular ( 3 pts.), inflammatory ( 2 pts.), Paget's disease of the nipple (2 pts.), papillary (pt.); ${ }^{b}$ unknown

breast-conserving surgery. The following adjuvant therapy was applied: postoperative radiotherapy (113 patients - 31.9\%), chemotherapy (137 patients - 38.7\%) and hormonotherapy (140 patients - 39.5\%), which in 127 patients (35.8\%) was combined with tamoxifen. In some cases, multimodal treatment was performed in an adjuvant setting.

\section{Metachronous primary malignancies after breast cancer}

In this article, metachronous malignancies are defined as primaries following the diagnosis of breast cancer in a time interval greater than or equal to 6 months.

The mean time interval between the diagnosis of breast cancer and the appearance of metachronous malignancies was 100.9 \pm 74.9 months (range: 6-543 months, median: 83 months). In most patients (220 of $354-62.1 \%$ ) metachro- nous malignancies developed later than 60 months after the initial diagnosis of breast cancer.

In 354 patients treated primarily for breast cancer, 380 cases of metachronous carcinomas were noted, including 354 cases of second cancer and, additionally, 24 cases of third cancer and 2 cases of fourth cancer.

The types of all 380 metachronous malignancies are presented in Table II.

The most frequent metachronous malignancy was breast cancer (194 cases - 54.8\%), which occurred as second (192 cases) or third ( 2 cases) cancer.

\section{Statistical methods}

In the studied population, two groups were distinguished: patients with metachronous contralateral breast cancer (all patients who developed breast cancer as metachronous primary morbidity) and patients with metachronous non-breast cancer. 
Table II. The types of 380 metachronous primary cancers, which developed in 354 patients after treatment for first breast cancer

\begin{tabular}{|c|c|c|c|c|c|}
\hline \multirow[t]{2}{*}{ Diagnosis of metachronous cancers } & \multirow[t]{2}{*}{ No. of all cases } & \multirow[t]{2}{*}{$\%$} & \multicolumn{3}{|c|}{ Metachronous primaries developed as morbidity: } \\
\hline & & & $2^{\text {nd }}$ & $3^{\text {rd }}$ & $4^{\text {th }}$ \\
\hline Total & 380 & 100.0 & 354 & 24 & 2 \\
\hline Breast cancer (in contralateral breast) & 194 & 51.1 & 192 & 2 & - \\
\hline Female genital organ cancers: & 83 & 21.8 & 73 & 10 & - \\
\hline Endometrial cancer & 30 & 7.9 & 29 & 1 & - \\
\hline Ovarian cancer & 29 & 7.6 & 23 & 6 & - \\
\hline Cervical uteri cancer & 21 & 5.5 & 19 & 2 & - \\
\hline Vaginal cancer & 2 & 0.5 & 1 & 1 & - \\
\hline Vulvar cancer & 1 & 0.3 & 1 & - & - \\
\hline Digestive organ cancers: & 24 & 6.3 & 22 & 2 & - \\
\hline Oesophageal and stomach cancer & 8 & 2.1 & 7 & 1 & - \\
\hline Colon cancer & 6 & 1.6 & 5 & 1 & - \\
\hline Rectal cancer & 6 & 1.6 & 6 & - & - \\
\hline Biliary tract and pancreatic cancer & 4 & 1.1 & 4 & - & - \\
\hline Skin neoplasms: & 21 & 5.5 & 18 & 2 & 1 \\
\hline Melanoma & 10 & 2.6 & 9 & 1 & - \\
\hline Carcinoma & 11 & 2.9 & 9 & 1 & 1 \\
\hline Lung cancer & 16 & 4.2 & 10 & 5 & 1 \\
\hline Urinary tract cancers: & 13 & 3.4 & 11 & 2 & - \\
\hline Kidney cancer & 9 & 2.4 & 7 & 2 & - \\
\hline Bladder cancer & 4 & 1.1 & 4 & - & - \\
\hline Thyroid cancer & 9 & 2.4 & 9 & - & - \\
\hline Lymphatic tissue neoplasms & 9 & 2.4 & 8 & 1 & - \\
\hline Head and neck, eye and brain cancers & 7 & 1.8 & 7 & - & - \\
\hline Soft tissue and bone sarcomas & 4 & 1.1 & 4 & - & - \\
\hline
\end{tabular}

The Pearson's Chi-square test for independence (for categorized variables) and variance analysis with Student's t-test (for continuous variables) were used for comparison of the two groups to assess the relation to the frequency of the factors analysed.The survival rate (overall and without metachronous maligancies) was evaluated with the Kaplan-Meier method, and the log rank test was applied to assess the influence of some factors on the evaluated results.

All calculations were performed by STATISTICA v.12 software (StatSoft, Inc. Tulsa, OK, USA) and the significance level at $\alpha=0.05$ was adopted for all statistical analyses.

\section{Results}

The probability of occurrence of new cancer averaged from $38.1 \%$ to $67.8 \%$ for 5 and 10 years after diagnosis of first breast cancer, respectively.

Figure 1 shows the probability of appearance of metachronous primaries in relation to their type (breast or non-breast). Lower tendency for the probability of the occurrence of the second breast cancer (or metachronous contralateral breast cancer) in comparison to the appearance of other types of metachronous primaries was noted
( $36.5 \%$ vs $40.1 \%$ for 5 years and $64.1 \%$ vs $72.2 \%$ for 10 years; $\mathrm{p}=0.05504$, log rank test).

Table III presents the results of the comparison of patients characteristics in relation to the type of metachronous malignancy: breast versus non-breast cancers.

Performed analysis showed statistically significant differences between these groups in relation to age, menopausal status, histological type of first breast cancer and implementation of tamoxifen. Patients who developed metachronous contralateral breast cancer, in comparison to patients with metachronous non-breast cancers, were significantly younger (mean age 50.9 vs 55.5 years; $p=0.00018$ ). The most of them were younger than 50 years of age $(56.2 \%$ vs $34.4 \%$; $\mathrm{p}=0.00005)$, in premenopause ( $69.6 \%$ vs $48.8 \% ; \mathrm{p}=0.00007)$, had lobular type of first breast cancer $(6.7 \%$ vs $1.3 \%$; $\mathrm{p}=0.04031)$ and did not use tamoxifen in adjuvant therapy for first breast cancer $(74.7 \%$ vs $51.3 \%$; $p<0.00001)$. Moreover, patients with lobular type of first breast cancer more frequently developed metachronous contralateral breast cancer than other type of metachronous malignancies ( 13 patients $-86.7 \%$ vs 2 patients $-13.3 \% ; p=0.04031$ ). Additionally, it was noted that the type of metachronous 


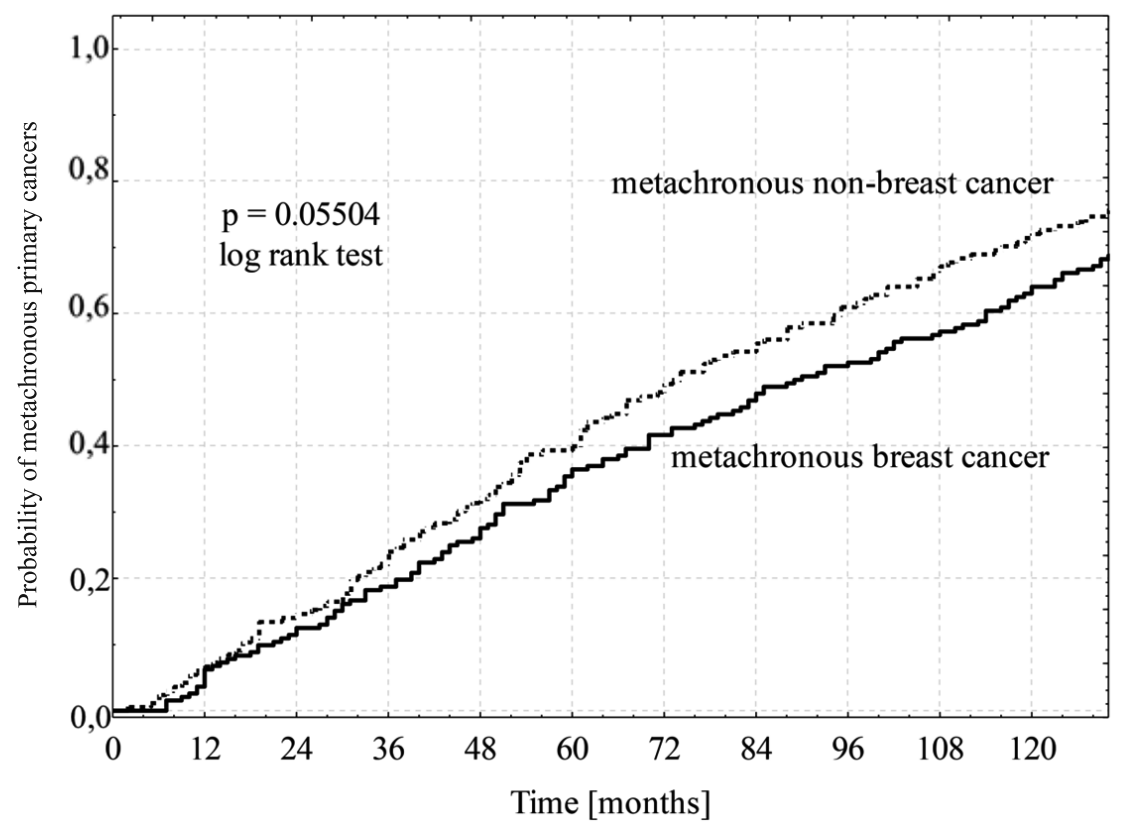

Figure 1. The probability of metachronous primary cancers in relation to the type of metachronous primaries: breast vs non-breast cancer

cancer (breast or non-breast) had significant influence on survival (Fig. 2).

The estimated 5-year and 10-year overall survival rates were: $92.9 \%$ and $80.1 \%$, respectively (for metachronous contralateral breast cancer) and $91.3 \%$ and $67.8 \%$, respectively (for metachronous non-breast cancer); $p=0.02710$, log rank test.

The follow-up period since the diagnosis of first breast cancer ranged from 7 to 558 months with mean value: $180 \pm$ 108.7 months and median: 168.5 months. During this period 195 patients (55.1\%) died and the causes of death were as following: second cancer (106 cases), third cancer (6 cases), coexistent non-cancer internal diseases (50 patients), and unknown (33 patients).

The estimated 5-and 10-year overall survival rates were: $91.8 \%$ and $74.5 \%$, respectively (Fig. 3 ).

The clinical observation showed that 71 patients (20.1\%) developed distant metastases in mean period of $28 \pm 27.3$ months (range: 1-136 months, median: 18 months). The localisations of this failure were as following: bones (28 cases), liver (12 cases), brain (11 cases), lungs (11 cases), distant lymph nodes (11 cases), skin (5 cases), pleura (1 case), peritoneum (1 case).

Furthermore, local/regional recurrence of breast cancer was noted in 59 patients (16.7\%). In 31 patients (8.8\%) this failure concerned the first breast cancer and it occurred in mean period of 50.2 \pm 50.2 months (range: $2-234$ months, median: 36 months). In remaining 28 patients (7.9\%) recurrence of second breast cancer was observed and it developed between 3 and 97 months (mean: 26.8 \pm 22.1 , median: 19.0 months) after diagnosis of second breast cancer.

\section{Discussion}

Published data indicate that women with breast cancer have an increased risk of developing second primaries. The results of meta-analysis performed by Molina-Montes et al. indicate that the risk of second cancer in breast cancer patients is increased by $17 \%$ in comparison with the general population, and this risk is relative to age at diagnosis of the first breast cancer and the time interval between the occurrence of the first and second malignancies. Women younger than 50 years have a $51 \%$ increase in risk in comparison to an $11 \%$ increase in women aged over 50 years. Furthermore, the risk of second malignancy after breast cancer is increased by $19 \%$ within the first 10 years and by $26 \%$ after 10 years [15].

Published data indicate that age as well as menopausal status at diagnosis of breast cancer are important predictors of second primaries [16, 24-34]. Langballe et al., who investigated the risk of second malignancies in relation to menopausal status in women with breast cancer, noted that premenopausal women had an $18 \%$ increase in risk of appearance of second malignancy and this increased risk was confined to endometrial and ovarian cancers. Moreover, in postmenopausal women the risk of cervical cancer was significantly reduced. The authors speculated that these observations resulted from intensified screening in comparison to the general population, and are related to different lifestyle factors and socioeconomic status [25]. 
Table III. The comparison of patient characteristics in relation to the type of metachronous primary cancers: breast cancer vs non-breast cancer

\begin{tabular}{|c|c|c|c|c|}
\hline \multirow{2}{*}{\multicolumn{2}{|c|}{ Parameters (at diagnosis of first breast cancer) }} & \multicolumn{3}{|c|}{ Metachronous primaries } \\
\hline & & $\begin{array}{c}\text { breast } \\
n=194(100 \%)\end{array}$ & $\begin{array}{c}\text { non-breast } \\
n=160(100 \%)\end{array}$ & $\mathrm{p}$ \\
\hline \multicolumn{5}{|l|}{ Age (years): } \\
\hline \multicolumn{2}{|l|}{ Mean value } & 50.9 & 55.5 & $0.00018^{\mathrm{a}}$ \\
\hline \multicolumn{2}{|l|}{$\leq 50$} & $109(56.2 \%)$ & $55(34.4 \%)$ & 0.00005 \\
\hline \multicolumn{2}{|l|}{$>50$} & $85(43.8 \%)$ & $105(65.6 \%)$ & \\
\hline \multicolumn{5}{|l|}{ Menopausal status: } \\
\hline \multicolumn{2}{|l|}{ Premenopausal } & $135(69.6 \%)$ & $78(48.8 \%)$ & 0.00007 \\
\hline \multicolumn{2}{|l|}{ Postmenopausal } & $59(30.4 \%)$ & $82(51.3 \%)$ & \\
\hline \multicolumn{5}{|c|}{ Family history of cancers: } \\
\hline \multicolumn{2}{|l|}{ Negative } & $130(67 \%)$ & $97(60.6 \%)$ & \\
\hline \multicolumn{2}{|l|}{ Breast cancers } & $30(15.5 \%)$ & $20(12.5 \%)$ & 0.09894 \\
\hline \multicolumn{2}{|l|}{ Other cancers } & $34(17.5 \%)$ & $43(26.9 \%)$ & \\
\hline \multicolumn{5}{|c|}{ Breast disease and other symptoms: } \\
\hline \multicolumn{2}{|l|}{ None } & $145(90.6 \%)$ & $176(90.7 \%)$ & \\
\hline \multicolumn{2}{|c|}{ Benign breast disease } & $4(2.5 \%)$ & $10(5.2 \%)$ & \\
\hline \multicolumn{2}{|c|}{ Hormonal disturbances } & $10(6.3 \%)$ & $7(3.6 \%)$ & 0.41446 \\
\hline \multicolumn{2}{|c|}{$B R C A 1$ or $B R C A 2$ mutation } & $1(0.6 \%)$ & $1(0.5 \%)$ & \\
\hline \multicolumn{5}{|l|}{ Histological type: } \\
\hline \multicolumn{2}{|l|}{ Ductal } & $159(82 \%)$ & $139(86.9 \%)$ & \\
\hline \multicolumn{2}{|l|}{ Lobular } & $13(6.7 \%)$ & $2(1.3 \%)$ & 0.04031 \\
\hline \multicolumn{2}{|l|}{ Other } & $22(11.3 \%)$ & $19(11.9 \%)$ & \\
\hline \multicolumn{5}{|c|}{ Stage of first breast cancer: } \\
\hline \multicolumn{2}{|l|}{ pT1-2 } & $143(73.7 \%)$ & $123(76.9 \%)$ & 0.83108 \\
\hline \multicolumn{2}{|l|}{ рT3-4 } & $43(22.2 \%)$ & $35(21.9 \%)$ & \\
\hline \multicolumn{2}{|l|}{ pNO } & $88(45.4 \%)$ & $79(49.4 \%)$ & 0.47897 \\
\hline \multicolumn{2}{|l|}{$\mathrm{pN}+$} & $105(54.1 \%)$ & $81(50.6 \%)$ & \\
\hline \multicolumn{5}{|l|}{ Treatment methods: } \\
\hline Radiotherapy & No & $127(65.5 \%)$ & $114(71.3 \%)$ & 0.24513 \\
\hline & Yes & $67(34.5 \%)$ & $46(28.8 \%)$ & \\
\hline Chemotherapy & No & $111(57.2 \%)$ & $106(66.3 \%)$ & 0.08244 \\
\hline & Yes & $83(42.8 \%)$ & $54(33.8 \%)$ & \\
\hline Tamoxifen & No & $145(74.7 \%)$ & $82(51.3 \%)$ & $<0.00001$ \\
\hline & Yes & $49(25.3 \%)$ & $78(48.8 \%)$ & \\
\hline Time interval betw & en diagnosis of first breast can & hous primary cance & & \\
\hline Mean value & & 108 & 92.5 & $0.06533^{\mathrm{a}}$ \\
\hline$\leq 60$ & & $69(35.6 \%)$ & $65(40.6 \%)$ & 0.32881 \\
\hline$>60$ & & $125(64.4 \%)$ & 95 (59.4\%) & \\
\hline
\end{tabular}

${ }^{a} \mathrm{p}$ value from Student's t-test, other $\mathrm{p}$ for chi-square test, ${ }^{\mathrm{b}}$ months after diagnosis of first breast cancer

In the studied group, $60.2 \%$ of women (213 of 354) were premenopausal at diagnosis of breast cancer, while $46.3 \%$ (164 of 354) were younger than 50 years of age. The comparison of characteristics of patients with metachronous breast vs non-breast malignancies showed significant differences in age and menopausal status. Younger age $(<50$ years) and premenopausal status were significantly more frequently observed in patients with matachronous contralateral breast cancer ( $56.2 \%$ and $69.9 \%$, respectively) in comparison to other types of metachronous malignancies (34.4\% and $48.8 \%$, respectively). Another significant difference was observed in tamoxifen intake; patients with metachronous contralateral breast cancer more frequently did not receive tamoxifen $(74.7 \%$ ) in comparison to $51.1 \%$ 


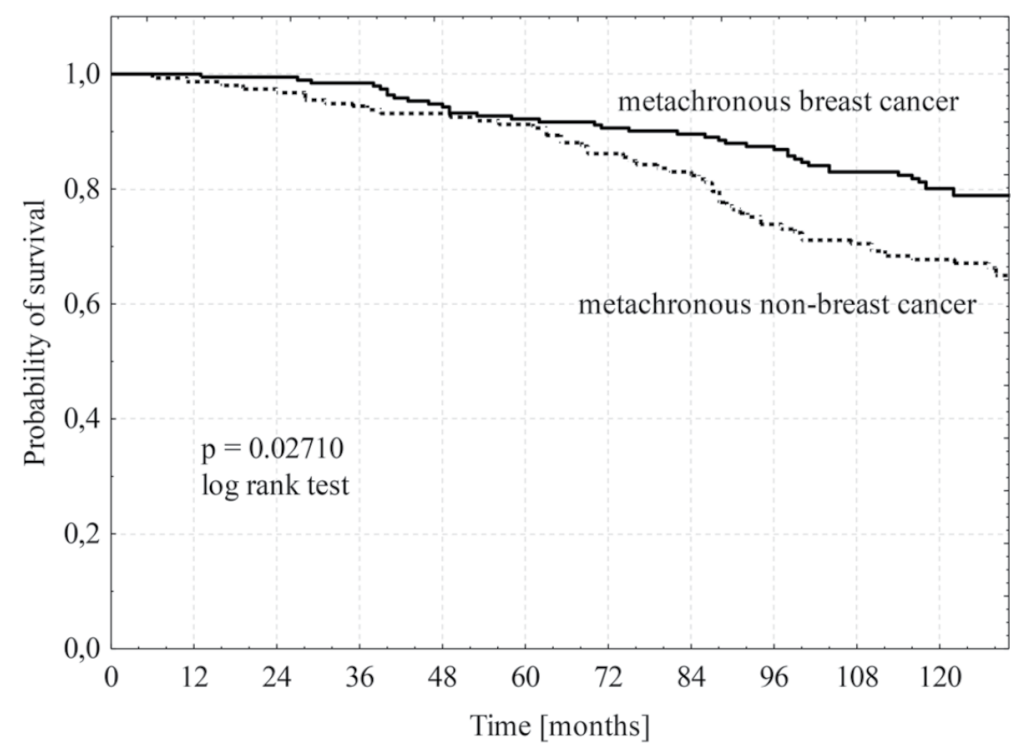

Figure 2. The probability of overall survival according to the type of metachronous primary cancer: breast vs non-breast cancer

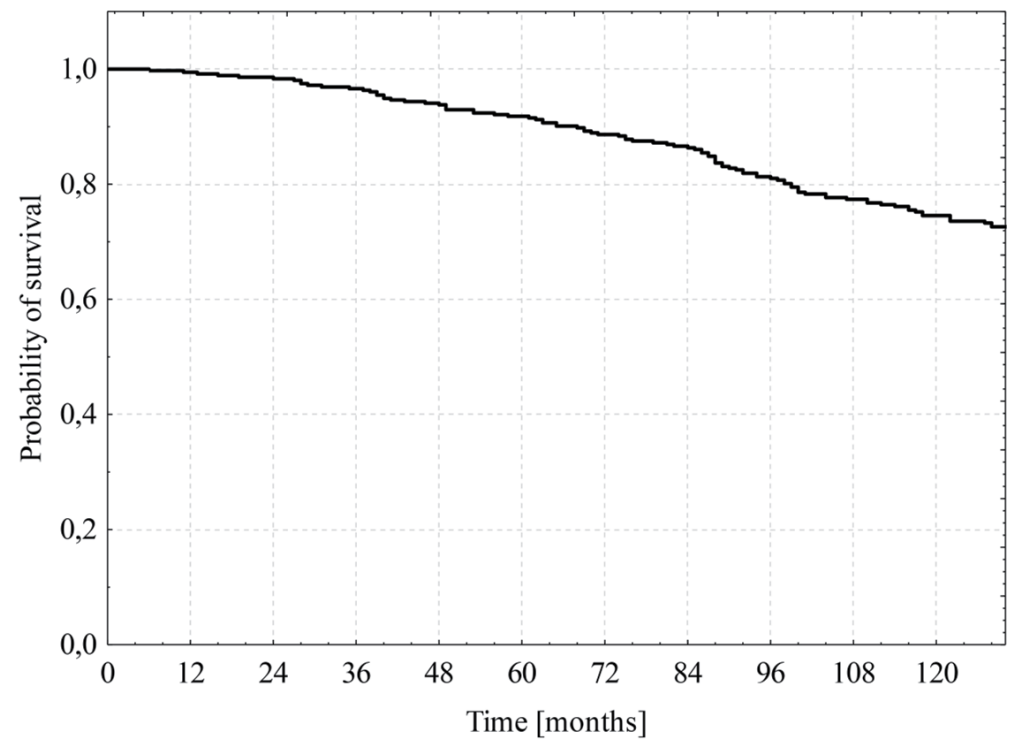

Figure 3. The probability of overall survival in patients with metachronous primaries developed after first breast cancer

who developed other types of metachronous malignancies. It is important to note that analysed patients were managed over the period of 47 years (breast cancers diagnosed between 1963 and 2010), and in this time interval the diagnostic methods and the spectra of treatment changed along with the indications, e.g. application of tamoxifen.

It is known that the elevated risk of subsequent cancer which developed in breast cancer survivors is related to hormonal (estrogen and progesteron) receptor status $[26,35]$.
Estrogen receptor-negative breast cancer is related to an increased risk of subsequent lung cancer. Schonfeld et al. presented that the lung cancer rate was significantly elevated after treatment of estrogen receptor-negative breast cancer. These authors showed a $22 \%$ increase in the risk of lung cancer in estrogen receptor-negative vs estrogen receptor-positive breast cancer patients [35]. It is important to mention that estrogen receptor-negative tumours are more frequent in younger patients with breast cancer.

In patients with expression of estrogen/progesterone receptors (ER/PR), the risk of second malignancy is as- 
sociated with hormonal therapy (especially tamoxifen). Tamoxifen is used for treatment of ER/PR-positive breast cancers and for primary breast cancer prevention. However, this drug may increase the risk of other primary malignancies [26, 36-38]. Endometrium and gastrointestinal organs (colorectum, stomach and liver) may be target sites for tamoxifen-induced carcinogenesis [36]. The risk of endometrial cancer increases with the time of tamoxifen usage; the relative risk rises from 2.0 for 2-5 years to 6.9 for at least 5 years, $p<0.001$ [37]. Additionally, tamoxifen users have a worse prognosis of endometrial cancer due to less favourable histology and a higher stage of disease.

The above-mentioned hormonotherapy as well as cytotoxic and radiation therapy used in breast cancer patients can increase the risk of occurrence of second malignancies $[3,4,6,20,22,24,26,36,37,39-46]$.

The results of the Danish national population-based study published by Grantzau et al. showed that radiotherapy-treated early breast cancer patients have a small but significantly elevated risk of second cancers [46]. The hazard ratio is 1.34 for radiotherapy-associated sites (lung cancer, esophageal cancer, soft tissue sarcoma) and for the time period of $10-14$ years $(H R=1.55)$ and over 15 years after therapy $(H R=1.79)]$. The results of Dutch Population-Based Study presented by Schaapveld et al., however, showed that in patients with breast cancer the 10-year cumulative incidence of second non-breast cancer was 5.4\% [24]. Among patients younger than 50 years, radiotherapy was associated with increased lung cancer risk ( $\mathrm{HR}=2.31)$, while chemotherapy - with decreased risk of all second nonbreast cancers $(H R=0.78)$. In patients aged 50 years and older, radiotherapy was associated with elevated risk of soft tissue sarcomas ( $\mathrm{HR}=3.43)$, while chemotherapy - with increased risk of melanoma, uterine cancer and acute myeloid leukemia. However, hormonal therapy was associated with elevated risk of all second non-breast cancers $(H R=1.1)$ and it especially raised the risk of uterine cancer $(H R=1.78)$ [24].

The most common second primary cancer in patients with breast cancer is contralateral breast cancer, which accounts for approximately $50 \%$ of all second cancers and $4.2 \%$ of all breast cancers [47]. Breast cancer patients have an increased risk (2-6 times) of occurrence of contralateral breast cancer, which occurs as metachronous malignancy at a rate of $0.13 \%$ per year and significantly more frequently in lower stages of disease [48].

In the presented group of metachronous malignancies, contralateral breast cancer comprised 54.8\% (194 cases) of all second cancers.

The risk of contralateral breast cancer is increased with positive family history, early age and stage IIB at diagnosis first breast cancer, estrogen/progesterone receptor-negative breast cancer, and lobular histology. Chemotherapy and tamoxifen reduce this risk, but the data concerning the role of radiotherapy as well as reproductive, environmental and other factors are inconsistent [27, 28, 30, 31, $32,45,49-52]$.

The possible impact of radiotherapy on development of contralateral breast cancer after treatment of first breast cancer remains undefined. Some authors showed the relationship between high dose volume and second cancer sites (lung, esophagus, pleura, bone, soft tissues, contralateral breast) but these risks decreased with increasing age and amount of time elapsed since treatment [20, 22, 45]. On the other hand, technological development in radiotherapy and the use of techniques with minimized scattered radiation can reduce this risk and, therefore, the frequency of cancers developed in high dose volume are strongly associated with environmental and lifestyle factors, and other therapeutic methods can influence this frequency $[29,50]$. Lobular type of breast cancer is positively (over 2 times) associated with the development of a contralateral breast cancer [32, 33, 34, 53]. In our group, metachronous contralateral breast cancer developed in 13 of $15(86.7 \%)$ patients with lobular first breast cancer.

The advances and effectiveness of breast cancer therapy resulted in the improvement of the survival rate. Elevated risk of occurrence of second malignancies in breast cancer survivors makes early detection of metachronous malignancies obligatory. These patients should be placed under much closer post-treatment surveillance in regard to screening procedures (e.g. mammography, breast MRI, colonoscopy, abdominal and transvaginal ultrasonography). Because of the clinical and physiological importance of this problem, early detection of second and higher-order primary malignancies is an important factor which influences the quality of life in breast cancer survivors.

\section{Conclusions}

1. The most frequent type of metachronous malignancy in patients with breast cancer is contralateral breast cancer (54.8\% cases).

2. Patients with contralateral breast cancer in comparison to other types of metachronous malignancies were younger (under 50 years) and premenopausal, had lobular type of first breast cancer and rarely received tamoxifen ( $25.3 \%$ vs $48.2 \%$ ). They had a significantly better prognosis than patients with other types of metachronous malignancies (10-year overall survival rates were $80.1 \%$ vs $67.8 \%, p=0.0271$ ).

3. The breast cancer survivors have an indication for some screening procedures, because the early detection of second and higher-order primary malignancies is an important factor which influences the quality of life in breast cancer survivors. 


\section{Conflict of interest: none declared}

\section{Beata Sas-Korczyńska, MD, PhD}

Clinic of Oncology

Maria Skłodowska-Curie, Memorial Cancer Centre

and Institute of Oncology

Kraków Branch

11 Garncarska Street

31-115 Kraków, Poland

e-mail:z5korczy@cyf-kr.edu.pl

Received: 18 Oct 2016

Accepted: 28 Nov 2016

\section{References}

1. Koubkova L, Hrstka R, Dobes P et al. Second primary cancers - causes, incidence and the future. Klin Onkol 2014; 27: 11-17.

2. Choi M, Craft B, Geraci SA. Surveillance and monitoring of adult cancer survivors. Am J Med 2011; 124: 598-601.

3. Travis LB. The epidemiology of second primary cancers. Cancer Epidemiol Biomarkers Prev 2006; 15: 2020-2026.

4. Lee JS, DuBois SG, Coccia PF et al. Increased risk of second malignant neoplasms in adolescents and young adults with cancer. Cancer 2016; 122: 116-123.

5. Amer MH. Multiple neoplasms, single primaries, and patient survival. Cancer Manag Res 2014; 6: 119-134.

6. Travis LB, Ng AK, Allan JM et al. Second malignant neoplasms and cardiovascular disease following radiotherapy. J Natl Cancer Inst 2012; 104: 357-370.

7. Hayat MJ, Howlander N, Reichman ME et al. Cancer statistics, trends, and multiple primary cancer analyses from the Surveillance, Epidemiology, and End Results (SEER) Program. Oncologist 2007; 12: 20-37.

8. Mariotto AB, Rowland JH, Ries LA et al. Multiple cancer prevalence: a growing challenge in long-term survivorship. Cancer Epidemiol Biomarkers Prev 2007; 16: 566-571.

9. Lee J, Park S, Kim S et al. Characteristics and survival of breast cancer patients with multiple synchronous or metachronous primary cancers. Yonsei Medical J 2015; 56: 1213-1220.

10. Filali $K$, Hedelin $G$, Schaffer $P$ et al. Multiple primary cancers and estimation of the incidence rates and trends. Eur J Cancer 1996; 32A: 683-690.

11. Trentham-Dietz A, Newcomb PA, Nichols HB et al. Breast cancer risk factors and second primary malignancies among women with breast cancer. Breast Cancer Res Treat 2007; 105: 195-207.

12. Cozen W, Bernstein L. Wang F et al. The risk of angiosarcoma following primary breast cancer. Br J Cancer 1999; 81: 532-536.

13. Calip GS, Law EH, Ko NY. Racial and ethnic differences in risk of second primary cancers among breast cancer survivors. Breast Cancer Res Treat 2015; 151: 687-696.

14. Buiatti E, Crocetti E, Acciai S et al. Incidence of second primary cancers in three Italian population-based cancer registers. Eur J Cancer 1997; 33: $1829-1834$

15. Molina-Montes E, Requena M, Sanchez-Cantalejo E et al. Risk of second cancers cancer after a first primary breast cancer: a systematic review and meta-analysis. Gynecol Oncol 2015; 136: 158-171.

16. Molina-Montes E, Pollan M, PayerT et al. Risk of second cancer among women with breast cancer: a population-based study in Granada (Spain). Gynecol Oncol 2013; 130: 340-345.

17. Torre LA, Bray F, Siegel RL. Global cancer statistics, 2012. CA Cancer J Clin 2015; 65: 87-108.

18. Zatoński WA, Sulkowska U, Didkowska J. Kilka uwag o epidemiologii nowotworów w Polsce. Nowotwory J Oncol 2015; 65: 179-196.

19. EBCTCG Early Breast Cancer Trialists' Collaborative Group. Effect of radiotherapy after mastectomy and axillary surgery on 10-year recurrence and 20-year breast cancer mortality: meta-analysis of individual patient data for 8135 women in 22 randomised trials. Lancet 2014; 383: 2127-2135.

20. EBCTCG (Early Breast Cancer Trialists' Collaborative Group). Effect of radiotherapy and of differences in extent of surgery for early breast cancer on local recurrence and 15-year survival: an overview of the randomised trials. Lancet 2005; 366: 2087-2106.
21. EBCTCG (Early Breast Cancer Trialists' Collaborative Group). Effect of radiotherapy after breast-conserving surgery on 10-year recurrence and 15-year breast cancer death: meta-analysis of individual patient data for 10,801 women in 17 randomised trials. Lancet $2011 ; 378$ : 1707-1716.

22. Darby S, McGale P, Taylor CW et al. Lon-term mortality from heart disease and lung cancer after radiotherapy for early breast cancer: prospective cohort study of about 300,000 women in US SEER cancer registries. Lancet Oncol 2005; 6: 557-565.

23. Evans $\mathrm{HS}$, Lewis $\mathrm{CM}$, Robinson $\mathrm{D}$ et al. Incidence of multiple primary cancers in a cohort of women diagnosed with breast cancer in southwest England. Br J Cancer 2001; 84: 435-440.

24. Schaapveld M, Visser O, Louwman MJ et al. Risk of new primary nonbreast cancers after breast cancer treatment: a Dutch population-based study. J Clin Oncol 2008; 26: 1239-1246.

25. Langballe $\mathrm{R}$, Olsen $\mathrm{JH}$, Andersson $\mathrm{M}$ et al. Risk of second primary non-breast cancer in pre- and postmenopausal women with breast cancer not treated with chemotherapy, radiotherapy or endocrine therapy. Eur J Cancer 2011; 47: 946-952.

26. Liu J, Jiang W, Mao K et al. Elevated risks of subsequent endometrial cancer development among breast cancer survivors with different hormone receptor status: a SEER analysis. Breast Cancer Res Treat 2015; 150: 439-445.

27. Buist DS, Abraham LA, Barlow WE et al. Diagnosis of second breast cancer events after initial diagnosis of early stage breast cancer. Breast Cancer Res Treat 2010; 124: 863-873.

28. Kurian AW, McClure LA, John EM et al. Second primary breast cancer occurrence according to hormone receptor status. J Natl Cancer Inst 2009; 101: 1058-1065.

29. Unnithan J, Macklis RM. Contralateral breast cancer risk. Radiother Oncol 2001; 60: 239-246.

30. Vichapat V, Gillett C, Fntiman IS et al. Risk factors for metachronous contralateral breast cancer suggest two aetiological pathways. Eur J Cancer 2011; 47: 1919-1927.

31. $\mathrm{Li} \mathrm{Cl}$, Malone $\mathrm{KE}$, Porter $\mathrm{PL}$ et al. Epidemiologic and molecular risk factors for contralateral breast cancer among young women. $\mathrm{Br} J$ Cancer 2003; 89: 513-518.

32. Claus EB, Stowe $M$, Carter $D$ et al. The risk of a contralateral breast cancer among women diagnosed with ductal and lobular breast carcinoma in situ: data from the Connecticut Tumor Registry. Breast 2003; 12: 451-456.

33. Chen $\mathrm{Y}$, Thompson W, Semenciw R et al. Epidemiology of contralateral breast cancer. Cancer Epidemiol Biomarkers Prev 1999; 8: 855-861.

34. Bernstein JL, Thompson WD, Risch $\mathrm{N}$ et al. Risk factors predicting the incidence of second primary breast cancer among women diagnosed with a first primary breast cancer. Am J Epidemiol 1992; 136: 925-936.

35. Schonfeld SJ, Curtis RE, Anderson WF et al. The risk of a second primary lung cancer after a first invasive breast cancer according to estrogen receptor status. Cancer Causes Control 2012; 23: 1721-1728.

36. Rutquis LE, Johansson $\mathrm{H}$, Signomklao T et al. Adjuvant tamoxifen therapy for early stage breast cancer and second primary malignancies. J Natl Cancer Inst 1995; 87: 645-651.

37. Bergman L, Beelem ML, Gallee MP et al. Risk and prognosis of endometrial cancer after tamoxifen for breast cancer. Comprehensive Cancer Centres' ALERT Group. Assessment of Liver and Endometrial cancer Risk following Tamoxifen. Lancet 2000; 356: 881-887.

38. Alkner $\mathrm{S}$, Bendahl PO, Ferno $\mathrm{M}$ et al. Tamoxifen reduces the risk of contralateral breast cancer in premenopausal women: results from a controlled randomised trial. Eur J Cancer 2009; 45: 2496-2502.

39. Rubino C, de Vathaire F, Diallo I et al. Increased risk of second cancers following breast cancer: role of the initial treatment. Breast Cancer Res Treat 2000; 61: 183-195.

40. Grantzau T, Thomsen MS, Vaeth M et al. Risk of second primary lung cancer in women after radiotherapy for breast cancer. Radiother Oncol 2014; 111: 366-373.

41. Hamilton SN, Tyldesley S, Li D et al. Second malignancies after adjuvant radiation therapy for early breast cancer: is there increased risk with addition of regional radiation to local radiation? Int J Radiat Oncol Biol Phys 2015; 91: 977-985.

42. Grantzau T, Overgaard J. Risk of second non-breast cancer after radiotherapy for breast cancer: a systematic review and meta-analysis of 762,468 patients. Radiother Oncol 2015; 114: 56-65.

43. Fowble B, Hanlon A, Freedman $G$ et al. Second cancers after conservative surgery and radiation for stages I-II breast cancer: identifying 
a subset of women at increased risk. Int J Radiat Oncol Biol Phys 2001; 51: 679-690.

44. Neugut Al, Robinson $\mathrm{E}$, Lee WC et al. Lung cancer after radiation therapy for breast cancer. Cancer 1993; 71: 3054-3057.

45. Berrington de Gonzalez A, Curtis RE, Gilbert E et al. Second solid cancers after radiotherapy for breast cancer in SEER cancer registries. Br J Cancer 2010; 102: 220-226.

46. Grantzau T, Mellemkjaer L, Overgaard J. Second primary cancers after adjuvant radiotherapy in early breast cancer patients: a national population based study under the Danish Breast Cancer Cooperative Group (DBCG). Radiother Oncol 2013; 106: 42-49.

47. Gao X, Fisher SG, Emami B. Risk of second primary cancer in the contralateral breast in women treated for early-stage breast cancer: a population-based study. Int J Radiat Oncol Biol Phys 2003; 56: 1038-1045.

48. Quan G, Pommier SJ, Pommier RF. Incidence and outcomes of contralateral breast cancers. Am J Surg 2008; 195: 645-650.
49. $\mathrm{Li} \mathrm{Cl}$, Malone KE, Weiss NS et al. Tamoxifen therapy for primary breast cancer and risk of contralateral breast cancer. J Nat I Cancer Inst 2001; 93: 1008-1013.

50. Yadav BS, Sharma SC, Patel FD et al. Second primary in the contralateral breast after treatment of breast cancer. Radiother Oncol 2008; 86: 171-176.

51. Molina-Montes E, Perez-Nevot B, Pollan M. Cumulative risk of second primary contralateral breast cancer in BRCA1/BRAC2 mutation carries with a first breast cancer: A systematic review and meta-analysis. Breast 2014; 23: 721-742.

52. Li Cl, Daling JR, Porter PL et al. Relationship between potentially modifiable lifestyle factors and risk of second primary contralateral breast cancer among women diagnosed with estrogen receptor-positive invasive breast cancer. J Clin Oncol 2009; 27: 5312-5318.

53. Horn PL, Thompson WD. Risk of contralateral breast cancer. Associations with histologic, clinical, and therapeutic factors. Cancer 1988; 62: 412-424. 